\title{
Understanding inaction in confronting ecosystem collapse: community perspectives from California's Salton Sea
}

\author{
Holly J. Buck $^{l}$
}

\begin{abstract}
Species loss is well-known as a defining challenge of our era. But in an era of increasing anthropogenic stressors, several ecosytems are at risk of collapsing because of human pressures. In the emergent literature on ecosystem collapse, few studies have focused on how ecosystem collapse is experienced by the communities living through it. In this paper I explore how communities understand ecosystem collapse, and possible ways of managing it, through a study of California's largest lake. The Salton Sea is at an ecological tipping point where it is rapidly shrinking and becoming more saline. This paper draws on 30 semistructured interviews in the Coachella and Imperial valleys around the lake, as well as observation of community meetings and archival material, to explore the following: How do people living around the Salton Sea view its collapse, including the failure to stop it? What measures do they see as having the potential to avert its collapse? These interviews indicate a clear understanding of the imminent decline, and a variety of conjectures about why nothing has been done, attributing this to its peripherality, power inequalities, the professionalization of Salton Sea solutions, and systematic incapacity on the part of the state of California. Respondents also surfaced three potential alternative pathways for restoration, as well as insights into the challenges of implementing them. The story of the Salton Sea, an ecosystem collapse in progress with no real action, may be repeated around the world, including in high-income jurisdictions like California, and it is important to understand the political and social contexts that determine whether or not a major effort is made to prevent collapse.
\end{abstract}

Key Words: ecosystem collapse; local perspectives; restoration; Salton Sea

\section{INTRODUCTION}

Ecosystems are being degraded around the world at an unprecedented rate, and attempts are underway to assess which might be at risk of collapse. The International Union for Conservation of Nature (IUCN) has developed the Red List of Ecosystems Criteria to assess ecosystems at risk of collapsing, and aims to assess ecosystem threat worldwide by 2025 (Sato and Lindenmayer 2018). Ecosystem collapse can be challenging to define, but at a basic level it involves "transformation of identity, loss of defining features, and/ or replacement by a novel ecosystem" (Bland et al. 2018:30). A growing body of literature has been exploring pathways of collapse, as well as how to identify tipping points and the mechanisms that underpin ecosystem resilience (Biggs et al. 2009, Oliver et al. 2015).

The one ecosystem assessed by the IUCN to be collapsed, thus far, is the Aral Sea. This inland sea faced water withdrawals that caused a $92 \%$ reduction in water volume within 50 years, transforming the ecosystem into one of saline lakes and desert plains, and eradicating most fish and invertebrates (Micklin 2010, Bland et al. 2018). California's inland sea, the Salton Sea, faces a transformation that looks similar in nature. The sea lacks natural outflows and inflows, and lies at a tipping point where increased salinity will eliminate all fish (Cohen 2014), shifting it from an ecosystem where fish are the trophic level on which birds feed to one where birds feed on a dwindling number of invertebrates, with significant impacts for migratory bird populations as well as human communities that will be exposed to increasing amounts of hazardous dust from the drying shores (Bradley and Yanega 2018, Reclamation 2007, Frie et al. 2019). Salinity is already at 60 parts per thousand (compared to 35 parts per thousand in the ocean). It will triple over the next 30 years, making the sea unsuitable for most forms of life, besides algae, bacteria, and viruses (SSMP 2017).

This is a long-anticipated crisis. Since the 1980s, expert technical committees and communities in the eastern Coachella and Imperial valleys have been evaluating options, but without any serious implementation, leading to both frustration and resignation on the part of residents. The interesting questions here, then, are not about predicting or explaining ecosystem collapse, or technically assessing various management options: there are entire archives of this material. Rather, the collapse-inprogress allows us to ask: How do communities make sense of both the pending collapse, and the inaction in the face of it? How do they evaluate the options for its future?

\section{Background: a history of inaction}

The Salton Sea is set in one of the harshest landscapes in North America, with three inches of rainfall a year and typical temperatures over $43^{\circ} \mathrm{C}$ (110 degrees Fahrenheit) in the summer months. It is common to hear that the Salton Sea is "a lake by mistake," though in fact, an intermittent lake in this sink has appeared and disappeared several times over the centuries. This most recent incarnation flowed from cut in a canal in the Colorado River, which poured into the Salton Sink from 1905 to 1907, filling the basin (Fig. 1). The valley boasts 500,000 acres of irrigated farmland, with over US\$2 billion worth of agricultural production, including melons and lettuce, sudangrass, Bermuda grass, alfalfa, and beef. Runoff from these agricultural operations has perpetuated the sea. The Salton Sea is in some ways a novel ecosystem, and one whose baseline in 1750 (the historical baseline used by the IUCN for assessing ecosystems) looks quite different. This makes discussions of "restoration" less than straightforward. 
However, over the last century, the ecosystem has become a vital component of the Pacific Flyway for migrating birds. In California, $96 \%$ of the historical wetlands have been lost to agriculture and development (Wilsey et al. 2017), and it is precisely this degradation of habitat in California writ large that makes the collapse of the Salton Sea ecosystem such a painful ecological loss.

Fig. 1. Map of Salton Sea and surrounding valleys.

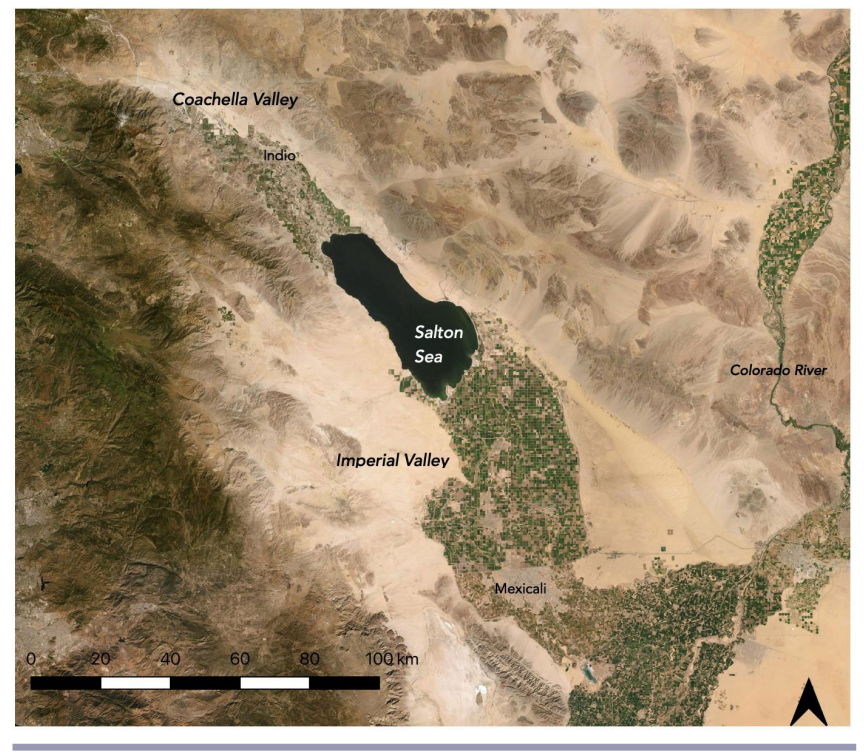

Water politics in the Western U.S. are dramatically accelerating the sea's decline. California is allotted a large portion of water from the Colorado River, and the Imperial Irrigation District (IID) in turn is allotted about $70 \%$ of California's share, 3.1 million-acre feet (i.e., the IID receives more water than the state of Arizona or the country of Mexico). However, the population of Imperial County is about 180,000 , and this wealth of water is used by about 500 farms. Meanwhile, there are 19 million thirsty customers on the urbanized coast. In this context, the largest rural-to-urban water transfer in the U.S. was born: the 2003 "Quantification Settlement Agreement" (QSA). The QSA is a set of agreements between the State of California, the Department of the Interior, and southern California water agencies. Under the water transfer, 30 million acre-feet over 75 years are sent from Imperial County to the San Diego and the Coachella Valley. The idea is that Imperial County farmers can make up for the water transferred away by implementing more efficient methods of production: lining canals to reduce seepage, installing advanced sprinklers, etc. As Pincetl and Katz (2007:268) point out, the Salton Sea would feel most acutely the effects of this new "hydrosocial contract" between users and the environment because the sea is sustained by agricultural water-use inefficiency. In short, the social-ecological role that this "wasted" water going into the Salton Sea plays was not well accounted for in the QSA (Cantor 2017). For an initial 15-year period, the IID was required to send "mitigation water" to the sea, water "saved" from fields they were paid to fallow. The state, for its part, was supposed to use these 15 years to figure out what to do about restoring the sea. During this period, the state did attempt to create a more comprehensive plan, with a committee in 2007 laying out an ambitious $\$ 8.9$ billion plan for a marine sea among several other options. This plan was never implemented. In 2018, the 15-year start-up phase ended, and the requirement to send any mitigation water to the Salton Sea expired, which reduces inflows to the sea by 200,000 acre-feet, exacerbating the sea's decline.

Currently, the state is implementing a 10-year plan, "Phase I" of the Salton Sea Management Program (SSMP), which calls for measures to expedite construction of habitat and suppress dust by 2028, and includes "shovel-ready" projects like habitat restoration and wetland construction, water backbone infrastructure, and saline impoundments to support fish and wildlife. However, physical, earth-moving progress has lagged far behind the state's own goals. Moreover, critics point out that it does not solve the underlying problem of the shrinking sea and its spiking salinity. It comes with a price tag of over $\$ 400$ million, and encouragingly, at the time of writing, most of this was finally appropriated via water bonds approved by California voters. Still, the 10-year, \$400 million plan is still just a fraction of the billions needed, perhaps $\$ 10$ billion, according to prior assessments by the U.S. Bureau of Reclamation. Essentially, Phase I is a stop-gap measure to cover dust and mitigate some air quality impacts while a long-term solution is devised. Subsequent phases are to be determined, and while this plan exists on paper, progress and funding have been so slow that the fate of the sea is still murky.

The collapse of this ecosystem is not merely an aesthetic curiosity or an environmental issue, but a public health threat. The receding shoreline is leaving behind fine silt containing sodium sulfate and selenium, which desert winds blow across surrounding communities. Over the next 10 years, 48,000 acres of dry lakebed "playa," or dust laden with farm chemicals, is projected to be exposed (SSMP 2017). By 2045, the exposed playa is projected to add up to 100 tons of dust per day into the air (Cohen 2014). This ecological disaster is unfolding upon landscape that is already economically distressed, with $25 \%$ unemployment and one in five residents living in poverty (LHC 2015). Pediatric asthma emergency room visits in this region are three times that of California as a whole already (Marshall 2017). Long-term costs of inaction are estimated at $\$ 29$ billion on the low end (Cohen 2014), to be borne by the state and taxpayers. In some ways, the collapse of the Salton Sea ecosystem is like climate change or other global environmental problems: foreseeable, but expensive and difficult to address. However, the scale of this ecological collapse is ostensibly more manageable: the entity that holds responsibility for addressing it is one of the world's richer and environmentally progressive jurisdictions, California. In this paper I explore why the state, even with environmental knowledge and forecasting, has been unable or unwilling to act to halt its collapse, and how stakeholders from local communities see the way forward.

\section{METHODS}

Qualitative methods typically feature research conducted in a natural setting, an emergent or iterative design, and holistic accounts of phenomena, and are well suited for research questions around how individuals or groups understand the meanings of a social or human problem (Creswell 2014). Although quantitative methods are sometimes said to require fitting lived experience into categories predefined by researchers, qualitative methods are known for allowing researchers to explore issues within the 
participants' own terms (Jayaratne and Stewart 1991). Semistructured interviews in particular were selected for this study because the research questions here are about how stakeholders view the future of their environment, including the Salton Sea, and how they assess the options for participating in shaping that environmental future. The strength of this method is that it can allow for exploration of meaning in the respondents' own terms: the categories and foci emerge from the interviews. The limitation of this method is that it is not suited for testing hypotheses or making claims about the whole population. However, semistructured interviews are a method appropriate to the focus of the study because the aim is not to represent how all community members see the future of the Salton Sea, or to quantify how many people are even familiar with its condition, though those would be good topics for further research. Rather, the aim of this study is to capture a range of views from a diverse group of stakeholders on how they understand the future ecology and the options for action.

Thirty semistructured interviews were conducted, as well as several other in-depth but informal conversations; 27 of these interviews were of appropriate recording quality to be transcribed and coded using NVivo 11 (refer to Appendix 1 for interview guide). Fieldwork was conducted in the Coachella, Imperial, and Mexicali valleys during July 2014, January 2016, and OctoberDecember 2016. Site visits included attending community activist meetings and official hearings about the Salton Sea, meetings about other environmental justice issues in the valleys, and visits to farms, water infrastructure, and existing and planned energy production sites. Interviews were conducted to the point of inductive thematic saturation (Saunders et al. 2018), i.e., to the point where new themes about action or inaction at the Salton Sea were no longer being identified.

Recruitment of participants involved both purposeful sampling and snowball sampling of stakeholders from the following groups: agriculture, science, environmental NGOs, business, government, and community organizing / education. Respondents were identified and selected through their participation in issues related to the sea, and were asked if they wanted to identify other respondents to speak with, particularly ones who may have divergent views. Purposeful sampling and snowball sampling do not seek to generate a representative sample, but rather to maximize the diversity of viewpoints (Moon et al. 2016). Part of the rationale for talking with key stakeholders, rather than a wider representative population, is that these key stakeholders are the ones shaping the terms and frames through which much of the debate around the problem and solutions takes place. Semistructured interviews can provide an in-depth look at how people develop these frames, and their understanding of the situation.

Given this method and sampling strategy, the sample is decidedly nonrepresentative of the greater demographics of the Imperial and Coachella valleys. For example, only about a quarter of respondents were of Latino/a descent because many local officials and advocates who work on Salton Sea issues are white males; the Imperial Valley is $80 \%$ Hispanic. This was partially addressed by reaching out to advocates from Latino/a communities who work on environmental justice and other civic issues, and women in particular. In Appendix 2, the respondents are listed with brief descriptors of their role in the community, though this does not represent a fixed typology of respondents, e.g., farmers could also be entrepreneurs or work in environmental activist roles. Rather, it is more helpful to see all these people as having a valuable situated perspective, rather than playing one discrete role in the social structure.

\section{RESULTS}

\section{Stakeholder understanding of ecosystem collapse}

In the communities surrounding the Salton Sea, many people are unaware of the Salton Sea and its ecology. Others are aware of the condition of the sea, but it is a low priority among other issues such as economic development, immigration policy, and access to drinkable water. One local official summarized the ways people come to know about the sea: environmentalists are paying some attention to it for ecological reasons; farmers in the Imperial Valley pay attention to it because of how it relates to water politics; farmers in the Coachella Valley pay attention to it because of water politics and development interest; Mexican-Americans living in Coachella may have lived here for 25 years and have never been to the Salton Sea; and people in the North Shore may be living there because it is the most affordable housing within commuting distance of the Coachella Valley, with the Salton Sea the least of their concerns. "You're trying to figure out how to get to work and pay for childcare for your three-year-old. ... I may know more about the Salton Sea than $99 \%$ of the people out there, and I don't think about it every day. It's not the highest priority in my life" (R16).

This study focused upon those who are active in Salton Sea issues, either directly because they work on or advocate for the Salton Sea, or indirectly because they are in industries affected by the Sea. Although representing diverse background and interests, these stakeholders tend to agree upon three basic points of concern: the sea will shrink rapidly, become unable to support birds and other forms of life, and dust emissions from the exposed lakebed will exacerbate the already poor air quality. People in community meetings also sometimes used the word contaminado, contaminated or polluted, to describe the sea. A few respondents with scientific backgrounds saw the situation in terms of transition or regime shift. At some point, one respondent stated, "we're going to have to transition from what we have now for an ecosystem to Great Salt Lake ecosystem or Aral Sea type of ecosystem," which means a different kind of wildlife (R7). This was not seen as being uncertain:

There's plenty of precedent, we know exactly what happens when these salt lakes dry down. It happened at the Aral Sea, it has happened in Lake Urmia in Iran, it happened in a smaller scale at Owens Lake. We know that we're headed for an environmental disaster. It's very well studied, it's not mysterious. It's not creeping up on us and nobody knew about it. (R12)

Many respondents saw this change in terms of "death," rather than ecosystem transition or collapse. The body of water is the dying entity: i.e., "That water transfer is going to kill it, because less water means more salt and more salt kills the fish, which then impacts the bird populations, impacts the Pacific Flyway, impacts the desert ecosystem. It's a chain of events that we have to prevent" (R14). Part of the sense of sea as dying may come from direct 
sensory observation, even though much of the concern is from the future. As one businessperson described:

\section{It's exceptionally beautiful. And then you go down to the beach, and you walk on the beach, and it's crunchy, and you realize it's not sand. It's the bones of a billion fish. And you just stand there, and you're like wow, this beautiful stark beauty... and you don't touch your feet. There's dead pelican carcasses and stork bodies everywhere, and you're like, this just doesn't make sense. This is just the failure of government, that's all the Salton Sea is, it's just failure of government. It's a great civics lesson for our country. (R19)}

This respondent, along with many others, saw the ecological collapse as not just environmental, but as a social failure on multiple scales. Indeed, the understanding of nearly every respondent was profoundly social-ecological, both in terms of the causes of the problem and its impacts on being a desirable place to live. As one community organizer summarized, "The lake will dry up, the animals will dry up, the people will get dust, the farms will dry up, the economic prosperity options would dry up" (R1). Yet the solution is often rendered in terms that place more focus on the ecology, with creating habitat as a first course of action in a complex social-ecological problem.

Respondents also contextualized the situation in ecological crises beyond the Salton Sea: the way the desert has been "torn up" from industrial farming, the loss of $95 \%$ of wetlands in California, and the desiccation of the Colorado River delta, described as complete destruction of "the biggest wetland biome" and "an ecological disaster" (R24). In these linkages with wider crises, respondents sometimes identified Salton Sea restoration as an opportunity, not just for local economic development, but as a "shining example" of how to handle managing water in the West (R11), or adapting to climate change (R4). Still, others noted that there is no signal that the opportunities will be acted upon. One respondent pointed that "they're always talking about adaptive management," but not funding actual biological monitoring that would be needed for real adaptive management (R12). Another noted the lack of participatory processes for turning the restoration into an opportunity

\section{It's an ecosystem that can be revived, and made into an important and thriving ecosystem in the region, but we don't see an interest in adding the views of those to the record such as tribes who have an interest in preserving the region. We are doubtful that those decisions that would lead to making positive change to the Salton Sea region are actually occurring. We can see the opposite. (R23)}

In the midst of observable decline and inaction, respondents identified roughly three alternative ways of moving forward with the sea, beyond the existing state's incremental plan for habitat construction and dust mitigation: (1) the idea of building a pipeline to import water from the ocean; (2) farmer, citizen-led, or private-sector solutions involving trees, tillage or alternative land management; and (3) political options involving changing the QSA. The remainder of this section will outline how community stakeholders view these pathways, and explore reasons why none of them have been implemented.
What are different stakeholders pursuing as possible pathways of action?

One alternative pathway of action is that of importing ocean water from the Sea of Cortez (locally called "sea-to-sea"). As advocates explain, if the problem is a loss of water, the solution is to put more water in. This does not fix salinity, unless you either desalinate the water or pipe salty water out again. But it does address elevation, and advocates argue that much of the canal or pipeline from the ocean would be going downhill, though there are some elevation gains. One official pointed out that "it's extremely doable technologically speaking. In other words, it's not rocket science, it's not science at all, it's totally doable. And that's where people are getting hung up. Because just because it's technically feasible doesn't mean that there aren't other factors involved"(R24). Key other factors include (1) the cost, (2) dealing with the excess salt, (3) an endangered porpoise, the vaquita, which lives in the Sea of Cortez, and (4) negotiating water import with Mexico. Proponents suggest that negotiating the water import through Mexico would be possible because Mexico would also have a stake in the issue. As for the cost, could a private entity construct the pipeline, and generate power and profit as a part of delivering the water? One entrepreneur has worked hard in partnership with the native Cocopah people in Mexico on a scheme that would benefit them via renting the land the pipeline would cross. The costs are a matter of debate, and long-range planning meetings feature varying estimates, from half a billion in capital costs to over $\$ 10$ billion. However, one proponent of sea-to-sea argued that putting water on the land was much cheaper than constructing wetlands, $\$ 5000$ per acre versus $\$ 35,000$, and the state just does not have the money for wetland construction on the scale needed. Although sea-to-sea proposals looked unrealistic just a few years ago, the California Natural Resources Agency offered a call for proposals, and garnered 11 proposals in early 2018. Longer term, there is also discussion about building a perimeter lake, at a cost of perhaps $\$ 2$ billion (James and Roth 2017); this would preclude investment in water import.

Farmers and other private citizens have suggested another avenue for restoration, given the state's inaction, which is private-sector revegetation of the sea. Farmers already are large-scale land managers, and they "want to raise their families here, they like it here and they're willing to put their work boots on and see what they can do to address these issues," in the words of one community member (R9). One farmer developed a private sectorled approach to planting trees interspersed with wetland habitat, drawing on existing expertise with permanent crops, including planting half a million pistachio trees, as well as hundreds of acres of dates and citrus. "Those are exotic species. What about Colorado River species? Cottonwoods and willows? Shit, just give me a tree source, and I need to clean up some of the salts, just like I would for citrus or for dates. I know how to do that, and I'll grow original Colorado River woods" (R5). Other propositions include planting local trees as windbreaks, or creating a ridge and till system. Six-foot wide furrows would break up the wind, and salt-loving plants could grow at the bottom of the furrows: salt cedars, iodide bush, etc. According to one farmer, this waterless dust mitigation could be done for $\$ 28.50$ an acre, or a fraction of the cost of constructing wetland habitat (R18). However, people across the political spectrum say that it has been challenging for private sector actors to provide solutions because of regulations: 
"you have to have deep pockets," as one development put it, and "a lot of folks that know and understand the business" (R8). Another project developer pointed out that it is hard to cross from pilot-scale to commercial expansion, because the state has not made the sea's future clear (R4).

Finally, there is a third little-discussed alternative pathway for avoiding ecosystem collapse: that of a political agreement to change the QSA. Although habitat construction, water import, and land management are all engineering solutions to a problem defined in terms of ecosystem crisis, the rapid shrinking induced by the water transfer could rightfully be seen as a political crisis. One expert suggested tying removal of water from the Imperial Valley to the state's ability to mitigate the dust, which could protect public health without taking away water rights, calling the state's current position "completely irresponsible." The state could buy the water back from San Diego, at a cost of perhaps $\$ 50$ million per year, and doing that for 10 years would still be cheaper than other ideas. "It's a direct, inexpensive, immediate relief that meets all the criteria that you would want, except San Diego doesn't get its water next year. That criterion's not met, but they still have their water rights." (R12) There is a precedent for this idea, as it was what happened at Mono Lake, where the water board tied the ability of Los Angeles to draw water to markers of elevation at the lake. However, the QSA was extremely difficult to negotiate, and it would be challenging for the parties involved to revisit its terms, to say the least.

\section{Why is so little being done to save the Salton Sea?}

Why has the state not taken more definitive action over all these years, when the impending collapse is predictable, and their responsibility has been so clear? Aside from the cost, respondents speculated upon three key reasons: (1) the ecosystem's peripherality, (2) the capture of the process by powerful legacy interests, and (3) systemic incapability on the part of the state. All of these relate to the extreme social inequality in the valley, in different ways.

First, there is geographic peripherality: the Salton Sea is in the "farthest corner of the state." Second, there is peripherality in terms of voter base, with a population of only 180,000 in the Imperial Valley, and another 189,000 in the eastern Coachella Valley census district (including Indio, Coachella, and the unincorporated communities near the Salton Sea of Mecca, Oasis, Thermal, and North Shore). Third, there is socialeconomic peripherality, as many people live in disadvantaged communities. Moreover, the ecosystem is also accorded a different value because it is so anthropogenically influenced, which allows it to be managed differently than a "natural" one. Cantor and Knuth argue that "postnatural management is a key vector of "sacrifice" at and of the Salton Sea" (2019:539). The Salton Sea has also not received the attention that places like Lake Tahoe or Mono Lake have garnered from green groups, perhaps because of its reputation for being unnatural or man-made; one activist also lamented a general failure to make the desert itself an iconic landscape (R22).

However, the sense of peripherality that people experience seems to have less to do with nature of the Salton Sea itself, and more to do with the basic social dynamics of inequality and constraints on participating in decision making. A community advocate describes how the "little guys" do not have much recourse when it comes to going up against the agribusiness lobby: "We could get elected into positions, but we can only push so hard and then we'll get stomped on big time" (R10). At the same time, this community member notes that for the first time there are Latino members of the state assembly and executive branch, as well as the U.S. Congress, and they are now in positions to make a difference (R10). However, a basic constraint is that people who are already saturated with other responsibilities are not really asking questions about environmental futures: people immigrate here under dangerous conditions just to work (R2). As another advocate explained, people often "don't have the time or the energy to look at those bigger issues, because they don't have potable water to drink, or they don't have a sewage system to treat their waste ... it prevents us, sometimes, from reaching the bigger pictures. Or from even joining coalitions or making partnerships to address those bigger issues, because we're too focused on more immediate needs" (R13). Formal participation in decisionmaking processes requires the education, time, money, and leisure to get organized, and then confronting people who have much more of those resources. Official meetings are often at water agency or institutional headquarters in Palm Desert or El Centro or Sacramento, and people sometimes travel hundreds of miles for a three-minute speaking slot. Despite all this, people do participate and use these structures. One nonprofit worker describes how participation at state water board meetings has been able to "kind of put the heart back into the equation, put the human element back into the equation," noting that hearing community voices "has been critical and crucial into changing the minds of the players" (R14).

Community members who are active in Salton Sea solution building are facing another challenge: burnout from dealing with this issue for decades without seeing meaningful progress.

When you've been at this at 10 years and you've seen no progress whatsoever, you tend to get upset and not want to do anything anymore. I can't let that happen, because I don't want to leave here. I don't want the state of California and the federal government going, oh you have a toxic situation out here, you have to move. Oh, by the way, and we're going to buy up all your property at 80 cents on the dollar. No, you're not. I'll stick here until they absolutely have to drag my ass out of here.

Do people out here talk about moving?

No. The long-term residents? Over my dead body. And the problem is, as the sea dries up, our dead bodies get closer in time. (R21)

In short, the lack of action can perpetuate a cycle of burnout and further inaction. For people living here, the collapse of the ecosystem is not a new story, but an ongoing concern.

Along with peripherality, respondents identified a second reason for the lack of action: the dominance of vested interests and legacy power relations. The IID and county leadership have always been entwined with agribusiness, and on one hand, they have been instrumental in pressing the state for action on the sea. Imperial Valley farmers are key to the sea's health, because their irrigation provides its inflows. At the same time, they are also a source of pollutants in the sea. Although the identity is historically one of farming, today, many of the farmers have moved to the coast and 
run their operations from afar, with about 435 farmers in the valley. A community advocate describes how agribusiness brings armies of workers, cities of workers, to Arizona, California, and other regions. "What's left for us is a lot of the residue, and that's what's created the Salton Sink. That's what's created that sea. Now, the ones who have created it, which is the farmers with the approval of the Imperial Irrigation District, somehow want the state to solve it" (R10). As a local businessperson explained: "This is anathema. If I were to say this publicly, I would probably be tarred and feathered, but the farmers have not taken any responsibility whatsoever for their problems with the Salton Sea," and they are not likely to take any accountability in the future: "They're just not. They pay 20 bucks an acre-foot for water. It's a pretty sweetheart deal" (R9). Through one lens, a group of elite farmers ran off with profits and left state taxpayers and local communities with a mess to clean up.

On the other hand, the people who seemingly have the most power, the farmers, experience a lack of agency, which may seem incongruous. Some farmers grew up here, and have stewarded the land for decades, and "they want to see it be beautiful and happy and booming again," as a local businessperson put it (R9). From the point of view of the farmers who are engaged with the Salton Sea, they have ideas and expertise in local land management, and yet are not listened to by decision makers. "They don't want to listen to farmers. ... They have to listen to someone who is an expert, that they pay a lot of money to hire as a consultant," people who have never seen the Salton Sea before (R18). In short, the professionalization of problem solving at the Salton Sea is seen as part of the problem. Along with these consultants, some see the IID and county leadership as an obstacle; one entrepreneur names "those 15 guys, 20 people, they're 99\% guys, they're all 60 year old white guys no less" as "the reason nothing ever gets done" (R19).

There is a third frightening prospect for the lack of action at the sea, which is that the state is not intentionally dragging its feet, but simply unable to mount a response, not able to deal with complex environmental challenges that require long-term vision and high-capital infrastructure. As one scientist put it, the state "is both financially and technically incapable of dealing with this issue," citing examples from the Delta tunnels project and the $\$ 64$ billion high-speed Los Angeles-San Francisco rail link as other complex and expensive engineering projects that the state did not have the capability of even starting, much less completing (R12).

Why, though, would the state systemically be incapable of these large engineering projects now, given the history of successfully modifying this region's environment throughout the 20th century? First, some suggest the state is just too large, compounding complexity as well as making regions far from the coast compete with other big projects like restoring the Sacramento Delta. Second, the population explosion through the last century means that the landscape is already built out; there is existing infrastructure to contend with or maintain when building new projects. Third, California has a demanding regulatory system, and permitting and contracting for projects can take years. Fourth, electoral time horizons are short.

The federal government is also seen to have a capability issue with large engineering projects. One official pointed out that people cite the Central Arizona Project and the Central Valley Water
Projects as examples of people "dreaming big and getting it done," but "those days are as gone as the 1950s Salton Sea is." Indeed, frustration about an incapable or broken federal government resonated on both sides of the political spectrum. In part, this has to do with an erosion of care: one expert on the sea commented that the 2016 presidential election evidenced "a real feeling that the government has not addressed the problems of people, particularly people who are not well-to-do, urban entrepreneurs," likening the neglect at the Salton Sea to that at Flint, Michigan. "In both cases, you have unelected officials making decisions that profoundly affect minority populations, where decisions are made on the basis of money as opposed to public health. I'm afraid that that's a very common phenomenon across the country" (R12). Yet the frustration with the broken government also seems related to a root sense of malaise about no longer being a nation of builders. The paralysis itself becomes another obstacle to overcome. A nonprofit worker describes the situation as one of fear of risk-taking:

The Salton Sea we see today was in part due to people dreaming big and people daring to build communities for the betterment of the future of their livelihood. They were farmers, engineers, building canals from the Colorado River all the way out to the middle of the desert to produce food for their families. If that's not dreaming, if that's not ambition, if that's not going after something big, then I don't know what is. I think we have lost that, I think in our government especially, in our leaders. I'm not sure why. I think a lot of people nowadays are afraid to take risks and dream big because they're afraid of failing. (R14)

A farmer, with very different political affiliations, expressed views rooted in a very similar narrative, describing the pioneers in the valley who made a trip to Washington, D.C. to negotiate for river water: "Can you imagine getting on a horse in 1919 and then going to a train station and going all the way across the country? The foresight. What's the foresight there? It's amazing," and yet there have been no new large water projects in California since the 1960s. (R3)

“The Salton Sea confounds the region's and the nation's traditional confidence that physical problems must inevitably yield to engineered solutions,"writes William DeBuys (1999:246). Viewed through one lens, the basin holds the salty ruins of the American Dream. These narratives about foresight and dreaming big omit key parts of the environmental history, such as the tension between private-sector and government-led irrigation development, which at times resulted in physical violence. But they resonate with people who are questioning if their institutions are capable of something like averting the collapse of an ecosystem.

Community stakeholders point to ecological collapse as a social failure on multiple scales. They largely understand the Salton Sea ecosystem as a social ecology, and understand the ecological foundation to be in need for restoration for continued social thriving. Not everyone used the language of "death" to describe the sea, but there was a coherent, widely shared view that the sea was slipping into a different regime. Although the solutions were often framed in terms of ecological restoration to "save" the sea, with a few simply discussing dust mitigation, this focus on the ecological aspects may actually allow some of the social factors 
that gave rise to the wider problem, such as unequal land ownership, the environmental history, and the water transfer itself, to go unaddressed.

\section{CONCLUDING REMARKS}

The stakes here are high, because they are not just about one ecosystem's decline, and the failure to save it. For many community stakeholders, the decline of the Salton Sea is not seen merely as an ecosystem collapse, but a kind of social-ecological death, where the fate of the ecosystem is both a cause of and result of the breakdown of social systems and institutions. The stakes involve the legitimacy of institutions, and what it means if the state is seen as willing to allow an ecological collapse. In this case, the credibility and legitimacy of the state of California is being stretched; this was clear in nearly every interview. The larger questions here are these: How are societies dealing with collapsing ecosystems around the world? What avenues for action hold promise, once a collapse is predictable? If the option is to manage an ecosystem more actively, or perhaps create and maintain a "designer ecosystem" (Ross et al. 2015), under which conditions might that be chosen or rejected?

Listening to the ideas of people who live here, and their hypotheses on inaction in the face of ecosystem collapse, points us to some directions for future research on the factors contributing to action or inaction.

First, this case illustrates the important role of monitoring the ecosystem. For example, if government action is slow, groups can gather their own data, like the nonprofit Comite Civico del Valle is doing with air quality monitors at schools in the Imperial Valley. Online groups that share observations about wildlife at the sea can also help generate awareness, while a more systematic approach to recording the sea's decline could be used to gather baseline data for future legal proceedings, as one resident pointed out. On the other hand, this case illustrates the constraints on monitoring in prompting action; it cautions against assuming that more data or better certainty about trends can solve the problem. Community monitoring is not the same as community engineering, some of the actions needed to mitigate dust at the sea are high-capital projects that citizens would be unable to fund. Future research could look at strategies of monitoring ecosystem collapse, and where and how they have successfully translated into action. Second, interdisciplinary social-ecological research could also look more at the psychological effects of ecosystem collapse, and how they feed back into the decision-making process. The Salton Sea shows the peril of resignation and burnout when action has stalled for too long, and when the problem has gathered a social perception of being intractable. Third, future research could also examine the relationship between social inequality and ecosystem collapse in other ecosystems. Much research has focused on the interactions between inequality and environmental degradation generally, with several pathways and feedback loops beginning to be identified, though much of the research on this topic is on the national or subnational scale, and focuses on economic inequality in particular (Hamann et al. 2018). Boyce's (1994) hypothesis that greater inequalities of power and wealth lead to greater environmental degradation seems relevant in this case. The wealthiest landowners do not even live in the Imperial Valley, which further enables its degradation. This case suggests the ecosystem level is a worthwhile scale for studying the relationships between land distribution, power, socioeconomic inequality, and ecosystem decline.

Future research could also join with Cumming and Peterson's (2017) call to synthesize lessons from social-ecological system collapse. In particular, with more than 25 significant saline lakes in decline around the world (AECOM 2019), there are opportunities to examine other saline lakes facing drying, such as the Great Salt Lake, and saline lakes that are being managed, such as Mono Lake in California. More broadly, there is an opportunity to synthesize lessons from studies like these, in order to discover in what contexts the factors for inaction identified by respondents here apply, where and how they have been transcended, and where societies simply decide to give into collapse and sacrifice particular areas. In an era where climate change threatens to accelerate ecosystem degradation around the world, we need a better understanding of the factors that contribute to inaction.

Responses to this article can be read online at: http://www.ecologyandsociety.org/issues/responses. php/11443

\section{Acknowledgments:}

Many thanks to the interview respondents for the generous gift of their time. I would also like to acknowledge the valuable feedback from two anonymous reviewers in improving this work.

\section{LITERATURE CITED}

AECOM. 2019. Consequences of drying lakes around the world. Report prepared for State of Utah / Great Salt Lake Advisory Council. AECOM, Los Angeles, California, USA. [online] URL: https://documents.deq.utah.gov/water-quality/standards-technicalservices/great-salt-lake-advisory-council/activities/DWQ-2019-010002. pdf

Biggs, R., S. R. Carpenter, and W. A. Brock. 2009. Turning back from the brink: detecting an impending regime shift in time to avert it. Proceedings of the National Academy of Sciences 106 (3):826-831. https://doi.org/10.1073/pnas.0811729106

Bland, L. M., J. A. Rowland, T. J. Regan, D. A. Keith, N. J. Murray, R. E. Lester, M. Linn, J. P. Rodríguez, and E. Nicholson. 2018. Developing a standardized definition of ecosystem collapse for risk assessment. Frontiers in Ecology and the Environment 16 (1):29-36. https://doi.org/10.1002/fee.1747

Boyce, J. K. 1994. Inequality as a cause of environmental degradation. Ecological Economics 11:169-178. https://doi. org/10.1016/0921-8009(94)90198-8

Bradley, T. J., and G. M. Yanega. 2018. Salton Sea: ecosystem in transition. Science 359(6377):754. https://doi.org/10.1126/ science.aar6088

Cantor, A. 2017. Material, political, and biopolitical dimensions of "waste" in California Water Law. Antipode 49(5):1204-1222. https://doi.org/10.1111/anti.12314 
Cantor, A., and S. Knuth. 2018. Speculations on the postnatural: restoration, accumulation, and sacrifice at the Salton Sea. Environment and Planning A: Economy and Space 51(2):527-544. https://doi.org/10.1177/0308518X18796510

Cohen, M. 2014. Hazard's toll: the costs of inaction at the Salton Sea. Pacific Institute, Oakland, California, USA.

Creswell, J. W. 2014. Research design: qualitative, quantitative, and mixed methods approaches. Fourth edition. SAGE, Thousand Oaks, California, USA.

Cumming, G. S., and G. D. Peterson. 2017. Unifying research on social-ecological resilience and collapse. Trends in Ecology \& Evolution 32(9):695-713. https://doi.org/10.1016/j.tree.2017.06.014

DeBuys, W. 1999. Salt dreams: land and water in low-down California. University of New Mexico Press, Albuquerque, New Mexico, USA.

Frie, A. L., A. C. Garrison, M. V. Schaefer, S. M. Bates, J. Botthoff, M. Maltz, S. C. Ying, T. Lyons, M. F. Allen, E. Aronson, and R. Bahreini. 2019. Dust sources in the Salton Sea basin: a clear case of an anthropogenically impacted dust budget. Environmental Science \& Technology 53(16):9378-9388. https://doi.org/10.1021/ acs.est.9b02137

Hamann, M., K. Berry, T. Chaigneau, T. Curry, R. Heilmayr, P. J. G. Henriksson, J. Hentati-Sundberg, A. Jina, E. Lindkvist, Y. Lopez-Maldonado, et al. 2018. Inequality and the biosphere. Annual Review of Environment and Resources 43:61-83. https:// doi.org/10.1146/annurev-environ-102017-025949

James, I., and S. Roth. 2017. Two paths for long-term fixes at California's shrinking sea. The Tennessean. [online URL: https:// www.tennessean.com/pages/interactives/salton-sea/two-paths-forlong-term-fixes-at-californias-shrinking-sea/

Jayaratne, T. E., and A. J. Stewart. 1991. Quantitative and qualitative methods in the social sciences: current feminist issues and practical strategies. Pages 85-106 in M. M. Fonow and J. A. Cook, editors. Beyond methodology: feminist scholarship and lived research. Indiana University Press, Bloomington, Indiana, USA.

Little Hoover Commission (LHC). 2015. Averting disaster: action now for the Salton Sea. Report \#228, LHC, Sacramento, California, USA.

Marshall, J. R. 2017. Why emergency physicians should care about the Salton Sea. Western Journal of Emergency Medicine 18 (6):1008-1009. https://doi.org/10.5811/westjem.2017.8.36034

Micklin, P. 2010. The past, present, and future Aral Sea. Lakes \& Reservoirs: Science, Policy, and Management for Sustainable Use 15:193-213. https://doi.org/10.1111/j.1440-1770.2010.00437. $\underline{\mathrm{X}}$

Moon, K., T. D. Brewer, S. R. Januchowski-Hartley, V. M. Adams, and D. A. Blackman. 2016. A guideline to improve qualitative social science publishing in ecology and conservation journals. Ecology and Society 21(3):17. https://doi.org/10.5751/ES-08663-210317

Oliver, T. H., M. S. Heard, N. J. B. Isaac, D. B. Roy, D. Procter, F. Eigenbrod, R. Freckleton, A. Hector, C. D. L. Orme, O. L. Petchy, et al. 2015. Biodiversity and resilience of ecosystem functions. Trends in Ecology \& Evolution 30:673-684. https://doi. org/10.1016/j.tree.2015.08.009

Pincetl, S., and B. Katz. 2007. The Imperial Valley of California: sustainability, water, agriculture, and urban growth. Pages 266-298 in R. Krueger and D. Gibbs, editors. The sustainable development paradox: urban political economy in the United States and Europe. Guilford, New York, New York, USA.

Reclamation. 2007. Restoration of the Salton Sea: summary report. U.S. Department of the Interior, Boulder City, Nevada, USA.

Ross, M. R. V., E. S. Bernhardt, M. W. Doyle, and J. B. Heffernan. 2015. Designer ecosystems: incorporating design approaches into applied ecology. Annual Review of Environment and Resources 40:419-443. https://doi.org/10.1146/annurev-environ-121012-100957

Salton Sea Management Program (SSMP). 2017. Salton Sea Management Program. Phase I: 10-Year Plan March 2017. State of California Department of Water resources, California Natural Resources Agency, and California Department of Fish and Wildlife, Sacramento, California, USA. [online] URL: http:// resources.ca.gov/docs/salton_sea/ssmp-10-year-plan/SSMP-Phase$\underline{\text { I-10-YR-Plan-with-appendices.pdf }}$

Sato, C. F., and D. B. Lindenmayer. 2018. Meeting the global ecosystem collapse challenge. Conservation Letters 11(1):e12348. https://doi.org/10.1111/conl.12348

Saunders, B., J. Sim, T. Kingstone, S. Baker, J. Waterfield, B. Bartlam, H. Burroughs, and C. Jins. 2018. Saturation in qualitative research: exploring its conceptualization and operationalization. Quality \& Quantity 52:1893-1907. https://doi. org/10.1007/s11135-017-0574-8

Wilsey, C. B., L. Taylor, N. Michel, and K. Stockdale. 2017. Water and birds in the arid West: habitats in decline. National Audubon Society, New York, New York, USA. 
Appendix 1. Interview guide.

California's Imperial and Coachella Valleys in 2050:

The future of the land, new technologies, and agricultural communities

Preliminary Questions: Let's begin with some background questions about your community and your views on the future of the landscape here.

1. How long have you lived here?

2. How has this valley changed over time?

3. What type of work do you do?

4. In 30 years, what do you think the landscape of this valley will look like?

5. What do you think is the future of agriculture in this valley?

6. What new technologies do you think will affect life in this valley in 2050 ?

7. What are your main concerns about the environment in the future?

a. Whose responsibility is it to deal with these concerns?

b. How do you plan to cope or take action about them?

Salton Sea Questions: In this second part of the interview, I'd like to hear your thoughts on the Salton Sea.

1. How concerned are you about the situation at the Salton Sea?

2. Do you expect the shrinking of Salton Sea to personally affect you in the future?

[If yes] How will it affect you?

3. What do you think is the best option for the Salton Sea?

4. Have you seen this option discussed? [If yes] Where? [If no] Why do you think it has not been discussed?

5. How should decisions about Salton Sea management or restoration be made?

6. What do you see as the obstacles for making progress at the Salton Sea?

7. Has the lack of action at the Salton Sea changed your opinion about our ability to solve environmental challenges? 
Supplemental questions asked of respondents with particular climate or agriculture expertise

\section{Climate change questions:}

1. How concerned are you about climate change?

2. Do you expect climate change to personally affect you in the future? [If yes] How will it affect you?

3. What do you think is the best option for dealing with climate change?

4. Have you seen this option discussed? [If yes] Where? [If no] Why do you think it has not been discussed?

5. Why do you think there has been so little action to date?

\section{Future of Agriculture Questions:}

1. What kind of agricultural production do you expect to see here in 2050 ?

a. What crops are grown?

b. Where will they be sent?

c. What techniques will be used to cultivate them?

d. Who will be growing them?

2. What factors or trends do you think will impact this production?

3. What would make your life and work better right now?

4. Can you describe what a healthy, best-case, thriving community here in 2050 would look like?

5. What are the obstacles to this vision?

6. What tools or conditions would you need to make this best-case vision a reality? 
Appendix 2. Reference list of respondents.

R1 Community advocate

R2 Community advocate

R3 Farmer

R4 Entrepreneur

R5 Farmer and entrepreneur

R6 Community advocate

R7 Local official

R8 Businessperson

R9 Geothermal expert

R10 Community advocate

R11 Local official

R12 Environmental expert

R13 Community advocate

R14 Community advocate

R15 Community advocate

R16 Local official

R17 Local official

R18 Farmer

R19 Entrepreneur

R20 Agricultural expert

R21 Community member

R22 Community advocate

R23 Local official

R24 Official

R25 Farmer

R26 Biofuels expert

R27 Community member

R28 Community advocate

R29 Biofuels expert

R30 Facilitator 
